\title{
OPEN Destruction of polyelectrolyte microcapsules and release of FITC-dextran from them by the influence of sodium dodecyl sulfonate
}

\begin{abstract}
Alexey V. Dubrovskii, Aleksandr L. Kim, Egor V. Musin \& Sergey A. Tikhonenko
Polyelectrolyte microcapsules can be applied as microcontainers for the delivery of a wide range of substances, and it is important to search for new methods for capsule destruction and releasing substances from them. In this work, we studied the possibility of using sodium dodecyl sulfonate (SDS) for the release of fluorescein isothiocyanate-dextran from six-layer microcapsules composed of PAH and PSS. It was shown that the presence of SDS in the medium, at a concentration of $3000 \mu \mathrm{g} / \mathrm{ml}$, leads to the destruction of polyelectrolyte microcapsules and the release of the substance from them ( $54 \%$ of the amount of the encapsulated substance), while the main part of the FITC-dextran released during the first hours of incubation. At an SDS concentration of $100 \mu \mathrm{g} / \mathrm{ml}$, the substance released is uniform and is $44 \%$ in $24 \mathrm{~h}$. At SDS concentrations from 50 to $100 \mu \mathrm{g} / \mathrm{ml}$, the process of destruction of microcapsules proceeds more slowly. At SDS concentrations from 10 to $50 \mu \mathrm{g} / \mathrm{ml}$, microcapsules are not degraded.
\end{abstract}

In 1998, Donath et al. First demonstrated the application of LbL self-assembly technology to create polyelectrolyte microcapsules. Microcapsules were created by alternating deposition of oppositely charged polyelectrolytes on different particles due to their electrostatic attraction ${ }^{1}$. The variety of polyelectrolytes used makes it possible to encapsulate active substances of different nature and create microcontainers for specific tasks. Effective microencapsulation of drugs, proteins and enzymes, corrosion inhibitors and pesticides is becoming increasingly important for a wide range of applications in medicine, cosmetology, agriculture, etc. ${ }^{2}$.

One of the main advantages of polyelectrolyte microcapsules is a variety of methods for the controlled release of an encapsulated substance, due to the variability of the composition of the microcapsule shell ${ }^{3}$. Release from microcapsules is necessary in the development of targeted therapy, which is to deliver a drug to the target organ and its local release ${ }^{4}$. In addition, this technology is used to create: self-healing materials, for example, for the release of corrosion inhibitors ${ }^{56}$; a new type of pesticide ${ }^{7}$, for the gradual release of herbicides and reduce the burden on the environment; genomic editing tools ${ }^{8}$ etc.

The release of the encapsulated substance is usually achieved by disrupting the shell of the microcapsule. For example, microcapsules made from biodegradable polyelectrolytes of a protein nature are destroyed by proteolytic enzymes ${ }^{9}$. A change in the $\mathrm{pH}$ of the incubation medium can also be a trigger for degradation of the microcapsule envelope, depending on the pKa of polyelectrolytes ${ }^{10}$. The shell can also be destroyed due to the physicochemical features of the nanoparticles included in the shell ${ }^{11-14}$. For example, titanium oxide nanoparticles can disrupt the shell structure of microcapsules when exposed to ultraviolet radiation ${ }^{15}$. Even bacterial spores can be used to break down the membrane of the microcapsules ${ }^{16}$.

In this work, we propose a new approach to the destruction of the shell of polyelectrolyte microcapsules using a surfactant-Sodium dodecyl sulfonate (SDS). At the moment, surfactants are used to create microcapsules with certain properties ${ }^{17,18}$, for example, microcapsules with salt reception ${ }^{18}$. At the moment, there are no works in the literature on the release of substances using surfactants. But this technology can be used to create self-healing materials, for example, for the release of anticorrosive substances under the influence of SDS or in dental practice for the gradual release of drugs or antibiotics on the surface of dental implants, fillings and other elements. 


\section{Materials and methods}

Materials. Polyelectrolytes polystyrenesulfonate sodium (PSS) and polyallylamine hydrochloride (PAH) with a molecular mass of $70 \mathrm{kDa}$, fluorescein isothiocyanate-dextran (150 kDa) Sigma (USA), Ethylenediaminetetraacetic acid disodium salt dihydrate (EDTA) purchased in Sigma (St. Louis, MS, USA), sodium dodecyl sulfonate (SDS), sodium carbonate, calcium chloride from "Reahim".

Preparation of $\mathrm{CaCO}_{3}$ Microspherulites. At stirring of $0.33 \mathrm{M} \mathrm{Na}_{2} \mathrm{CO}_{3}$, the $0.33 \mathrm{M} \mathrm{CaCl}_{2}$ containing $0,2 \mathrm{mg} / \mathrm{ml}$ of FITC-dextran was added. The stirring time was $30 \mathrm{~s}$. The suspension was maintained until complete precipitation of the formed particles. The process of "ripening" of microspherolites was controlled with the help of a light microscope. Then, the supernatant was decanted, the precipitate was washed with water and used to prepare PMC. The microparticles were obtained with an average diameter of $4.5 \pm 1 \mu \mathrm{m}$.

Preparation of polyelectrolyte microcapsules. The polyelectrolyte microcapsules were obtained by layer-by-layer adsorbing the negatively or positively charged polyelectrolytes onto $\mathrm{CaCO}_{3}$ microspherulites, followed by dissolution of $\mathrm{CaCO}_{3}$. Layer-by-layer adsorption of $\mathrm{PAH}$ and PSS on the $\mathrm{CaCO}_{3}$ microspherulites surface was carried out in polyelectrolytes solutions (concentration $2 \mathrm{mg} / \mathrm{mL}+0.5 \mathrm{M} \mathrm{NaCl}$ ). After each adsorption the $\mathrm{CaCO}_{3}$ particles with adsorbed polyelectrolytes were triple washed with a $0.5 \mathrm{M} \mathrm{NaCl}$ solution, which was necessary to remove unabsorbed polymer molecules. The particles were separated from the supernatant by centrifugation. After applying the required number of layers, the carbonate kernels were dissolved in a $0.2 \mathrm{M}$ EDTA solution for $12 \mathrm{~h}$. The resulting capsules were washed three times with water to remove core decay products. The microcapsules were obtained with an average diameter of $4.5 \pm 1 \mu \mathrm{m}$.

Fluorescence microscopy. Images were taken using an «Axiovert $200 \mathrm{M}$ Cell Observer» inverted fluorescence microscope with high-speed camera AxioCam HSM of Carl Zeiss company using 60×/1.4 Oil objective. Diode laser 488 were used for excitation. Images were acquired at a resolution of $1388 \times 1040$ pixels.

Incubation of PMC in SDS solution. The polyelectrolyte microcapsules with encapsulated FITC-dextran were incubated in SDS solution with concentrations $0,10,50,100$ and $3000 \mu \mathrm{g} / \mathrm{ml}$ with constant shaking on the vortex (500 rpm for the required time).

Registration of the FITC-dextran release from polyelectrolyte microcapsules. After $0,1,3$ and $24 \mathrm{~h}$ of incubation, a suspension of microcapsules was taken from the incubation solution and filtered using a membrane filter. Subsequently, the fluorescence intensity of the filtered solution was measured. Fluorescence spectra were recorded on an Infinite 200 Tecan instrument in a Black 96-Well Immuno Plates when excited with light at a wavelength of $480 \mathrm{~nm}$.

\section{Results}

Destruction of polyelectrolyte microcapsules by an SDS. The first stage of the research is to study the preservation of the integrity of polyelectrolyte microcapsules (PMC) over time in an SDS solution. For this, PMCs of composition (PSS/PAH) 3 containing FITC-labeled dextran were prepared. These microcapsules were incubated in SDS solutions with concentrations of $0,10,50,100$ and $3000 \mu \mathrm{g} / \mathrm{ml}$ and a sample of each concentration was photographed after $0,10,30,60,180$ and $1440(24 \mathrm{~h})$ minutes of incubation. All obtained micrographs are presented in "Appendix" to this work. It was found that during $60 \mathrm{~min}$ of incubation, PMCs were not destroyed in the entire studied range of SDS concentrations. However, at concentrations of SDS from 10 to $100 \mu \mathrm{g} / \mathrm{ml}$, aggregation of microcapsules was observed and the size of aggregates increased with increasing concentration of SDS (Fig. 1). At a concentration of sds of $3000 \mu \mathrm{g} / \mathrm{ml}$, there was no aggregation of microcapsules, which may be due to the concentration of micelle formation of sds $(\mathrm{CMC}=2300 \mu \mathrm{g} / \mathrm{ml})^{19}$.

After 180 min of incubation of the microcapsules, the destruction of the capsules in the SDS solution of $3000 \mu \mathrm{g} / \mathrm{ml}$ was observed (Fig. 2).

At this concentration, a large number of polyelectrolyte particles ranging in size from 6 to $20 \mu \mathrm{m}$ with a complex irregular shape were observed, while undisturbed PMCs were also observed. At other concentrations, no changes were observed after $180 \mathrm{~min}$ of incubation.

After $24 \mathrm{~h}$ of incubation, degradation of the microcapsules was observed at SDS concentrations of $100 \mu \mathrm{g} /$ $\mathrm{ml}$ and $3000 \mu \mathrm{g} / \mathrm{ml}$ (Fig. 3).

In the case of $100 \mu \mathrm{g} / \mathrm{ml}$, both irregularly shaped polyelectrolyte particles and polyelectrolyte microcapsules are observed. In the case of 24 -h incubation of PMC in a SDS solution with a concentration of $3000 \mu \mathrm{g} / \mathrm{ml}$, only polyelectrolyte particles of irregular shape were observed.

For clarity, Fig. 4 shows micrographs of microcapsules in a SDS solution of $3000 \mu \mathrm{g} / \mathrm{ml}$ and water before and after $24 \mathrm{~h}$ of incubation.

As can be seen from the figure, PMCs incubated in water are not destroyed during all $24 \mathrm{~h}$. For $24 \mathrm{~h}$ of incubation in a SDS solution with a concentration of $3000 \mu \mathrm{g} / \mathrm{ml}$, almost complete destruction of the capsules occurs; a large number of irregular particles, which are a polyelectrolyte complex, are observed in the solution. Thus, it can be concluded that the concentration of SDS $3000 \mu \mathrm{g} / \mathrm{ml}$ almost completely destroyed the PMC of the composition (PSS/PAH) 3 within $24 \mathrm{~h}$.

The cause of the destruction of the microcapsule may be the electrostatic interaction of SDS molecules with PAH amino groups. The work of A. Sharipova et al. describes the processes of complex formation between polyallylamine and sodium dodecyl sulfonate ${ }^{20}$. And the work of Eri Yoshida found out that an increase in the 


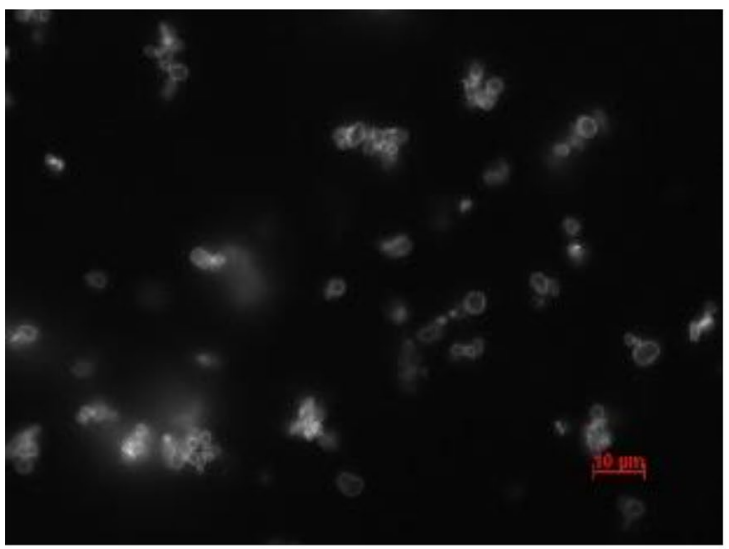

$10 \mu \mathrm{g} / \mathrm{ml}$

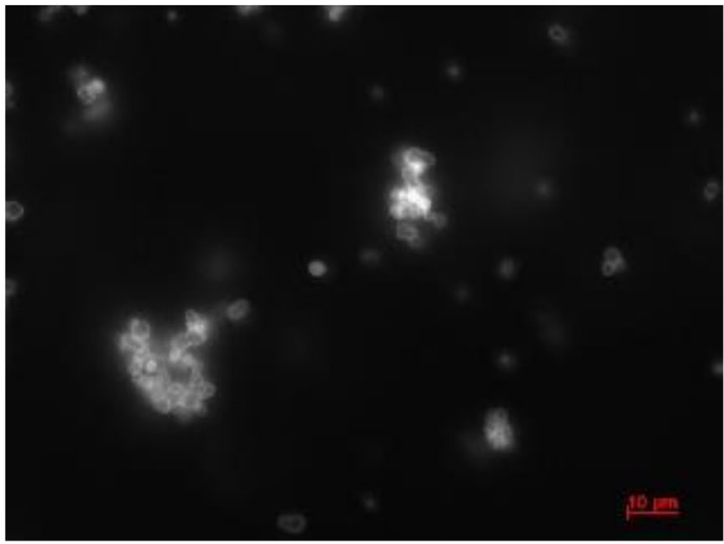

$100 \mu \mathrm{g} / \mathrm{ml}$

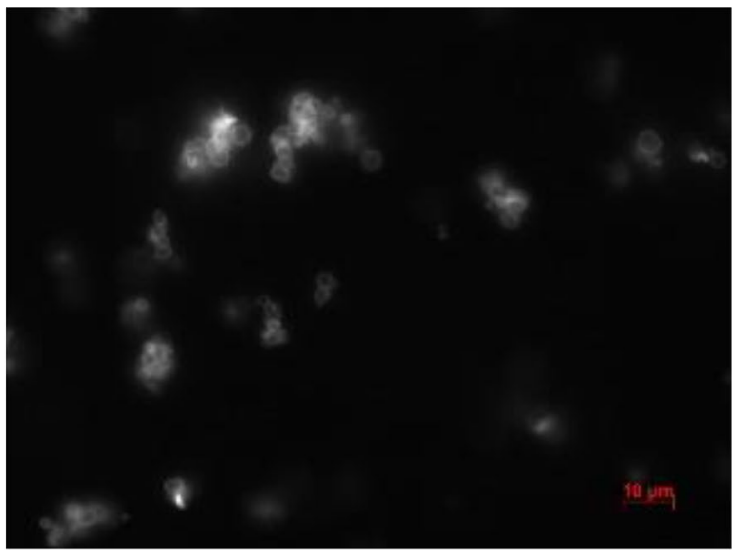

$50 \mu \mathrm{g} / \mathrm{ml}$

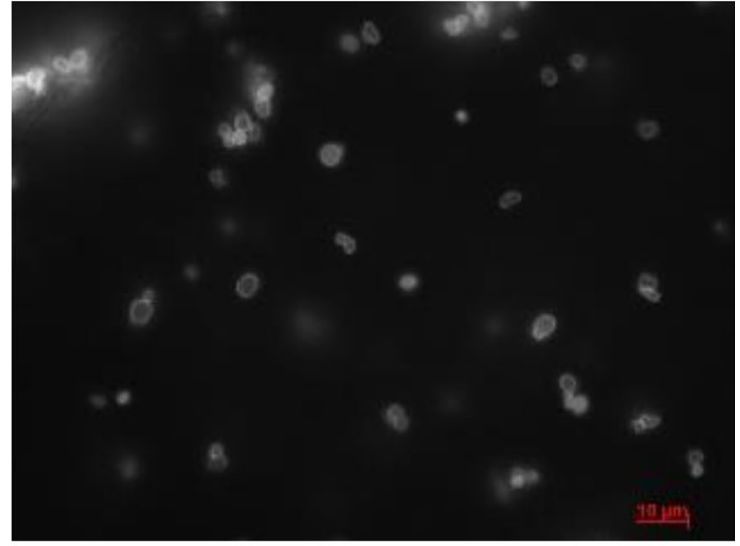

$3000 \mu \mathrm{g} / \mathrm{ml}$

Figure 1. Image of polyelectrolyte microcapsules in SDS solution after $60 \mathrm{~min}$ of incubation(concentrations 10 , $50,100$ and $3000 \mu \mathrm{g} / \mathrm{ml})$.

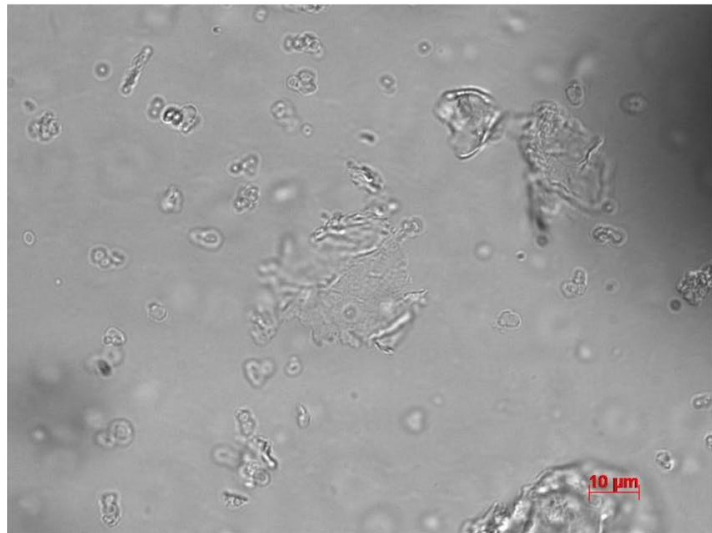

A

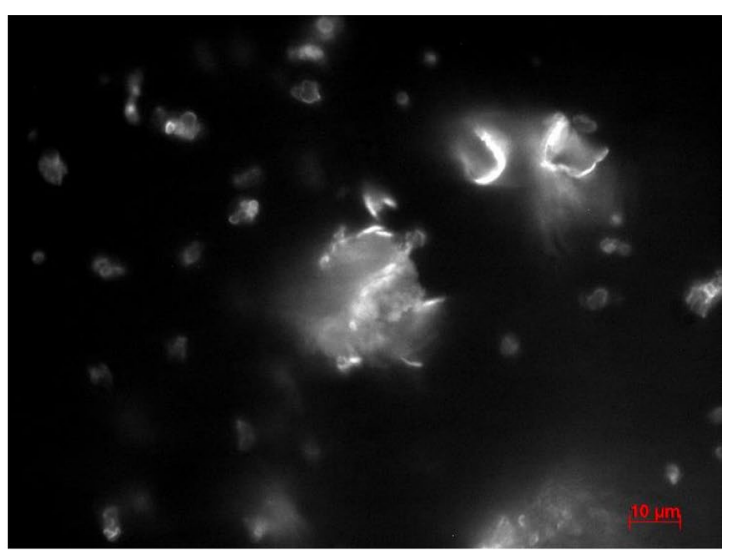

B

Figure 2. Image of polyelectrolyte microcapsules in $3000 \mu \mathrm{g} / \mathrm{ml}$ SDS solution after $180 \mathrm{~min}$ of incubation (A) light microscopy, (B) fluorescence microscopy).

concentration of SDS in solution initiates the torsion of the polyelectrolyte and then the formation of a micellar aggregate, in the form of an SDS core coated with a PAH shell ${ }^{21}$. Based on the works described above, we put forward a hypothesis that SDS forms a complex with uncompensated site of PAH microcapsules, which leads to a weakening of the electrostatic interaction between subsequent bound regions of PSS and PAH and to the appereance of new uncompensated regions of polyelectrolytes. Further formation of PAH-SDS complexes leads to twisting and the formation of a micellar aggregate. The formation of the aggregate is accompanied by 


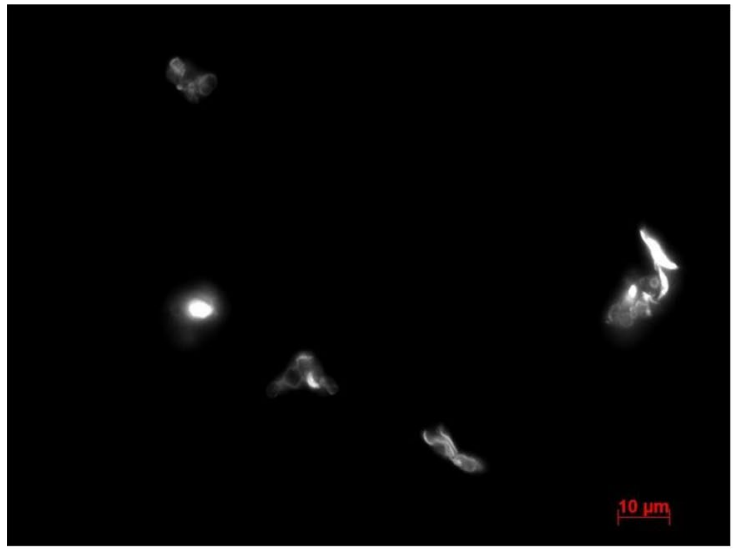

A

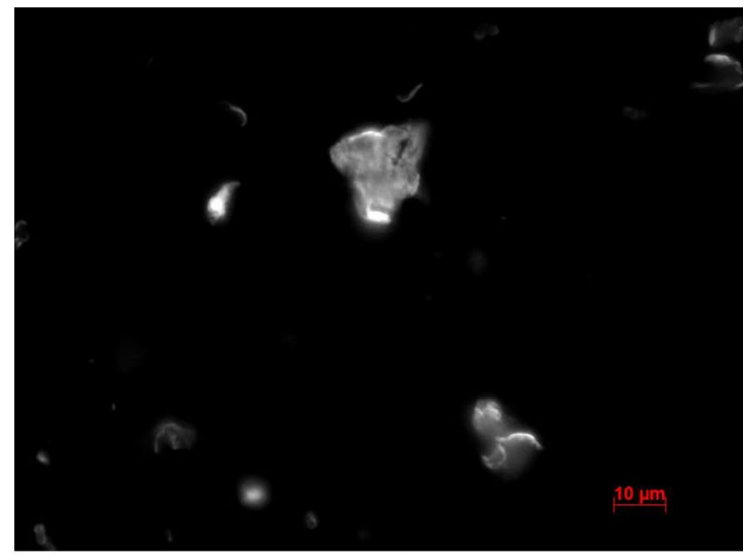

B

Figure 3. Image of polyelectrolyte microcapsules in $100 \mu \mathrm{g} / \mathrm{ml}$ (A) and $3000 \mu \mathrm{g} / \mathrm{ml}$ (B) SDS solution after $24 \mathrm{~h}$ of incubation.

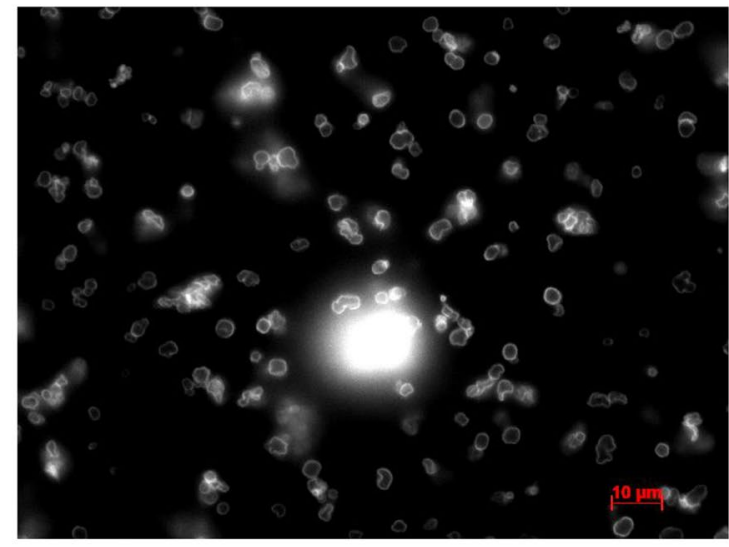

A

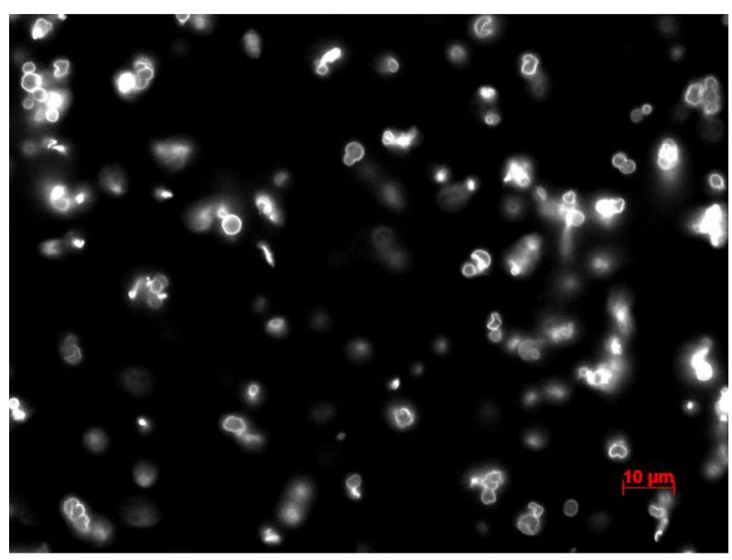

C

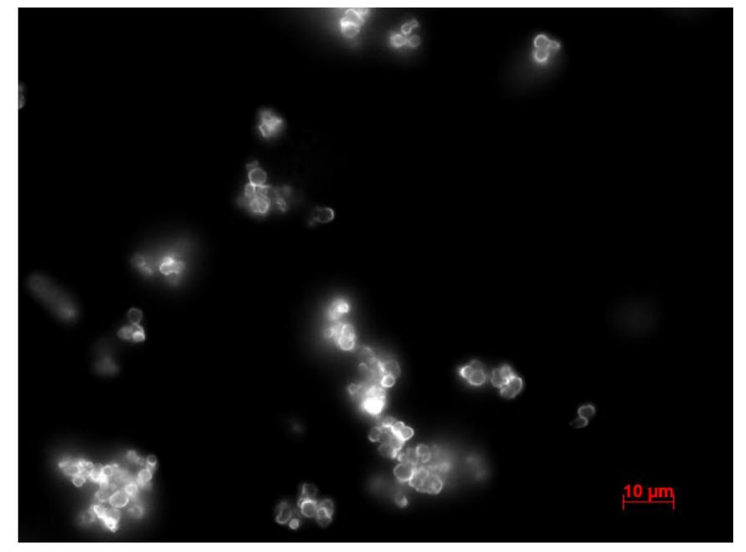

B

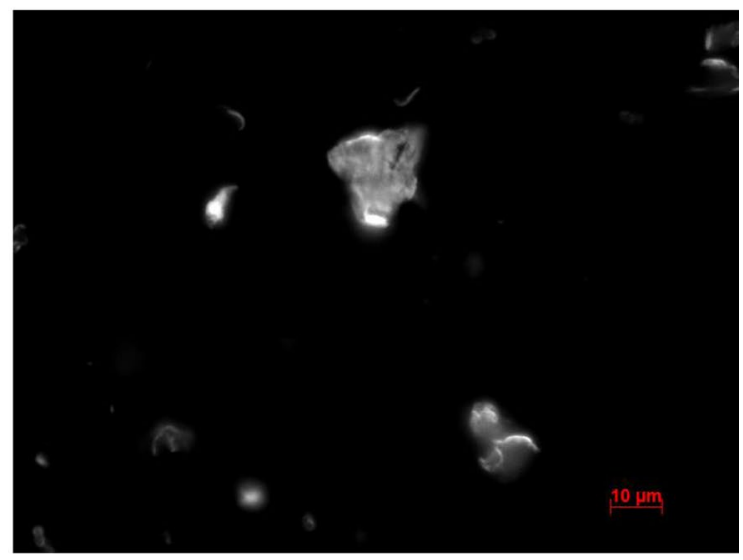

D

Figure 4. Image of polyelectrolyte microcapsules in water and $3000 \mu \mathrm{g} / \mathrm{ml} \mathrm{SDS}$ solution before and after $24 \mathrm{~h}$ of incubation. (A) PMC in water solution before incubation. (B) PMC in $3000 \mu \mathrm{g} / \mathrm{ml}$ SDS solution before incubation. (C) PMC in water solution after $24 \mathrm{~h}$ incubation. (D) PMC in $3000 \mu \mathrm{g} / \mathrm{ml}$ SDS solution after $24 \mathrm{~h}$ incubation).

the release of the polyelectrolyte from the microcapsules, which with repetition, leads to their destruction. In addition, constant stirring of the solution speeds up this process.

Release of FITC-labeled dextran from PMC. The next stage of our research was to study the release of encapsulated FITC-labeled dextran from PMC due to the effect of SDS. We used an SDS solution with concen- 


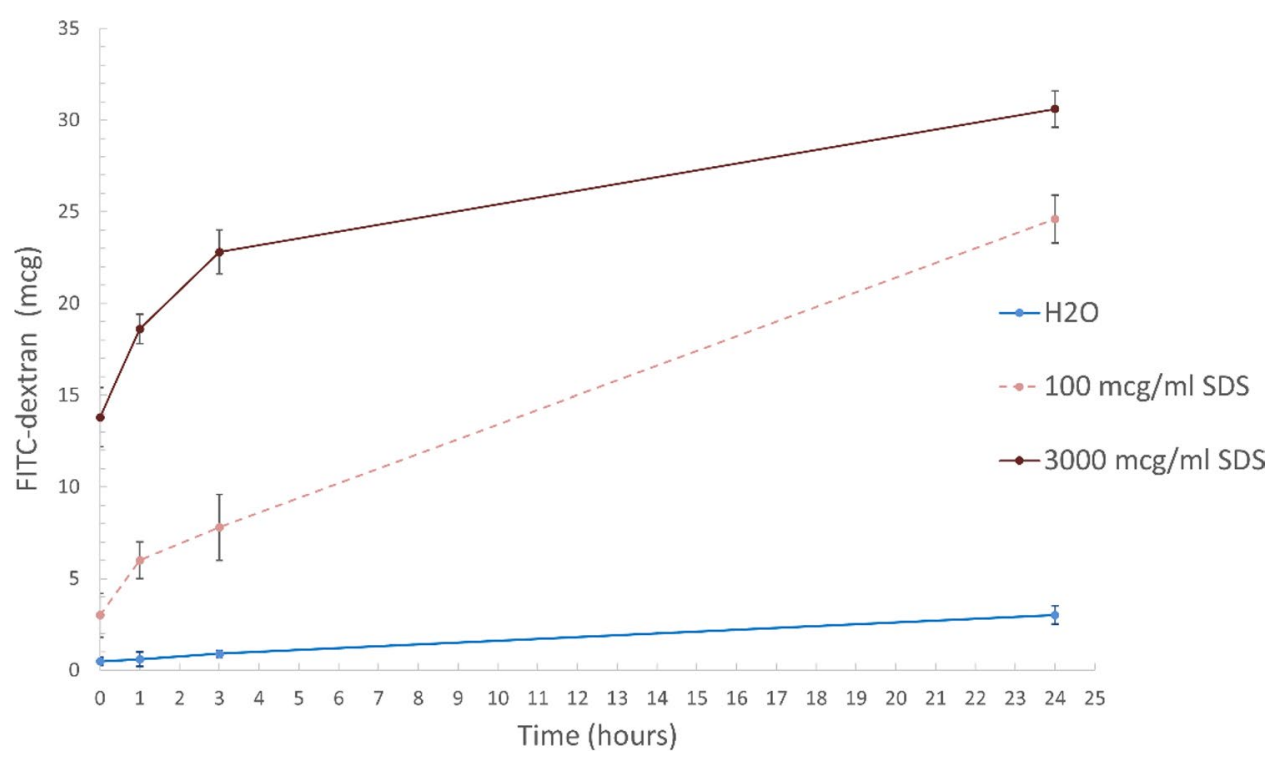

Figure 5. The release of FITC-dextran over time from polyelectrolyte microcapsules in SDS solution (100 and $3000 \mu \mathrm{g} / \mathrm{ml})$.

trations of 0,100 , and $3000 \mu \mathrm{g} / \mathrm{ml}$, since at these concentrations, micrographs showed destruction of the PMC shape after $24 \mathrm{~h}$ of incubation. The change over time in the amount of FITC-labeled dextran is shown in Fig. 5.

The figure shows that at the moment of adding capsules to the SDS solution $(3000 \mu \mathrm{g} / \mathrm{ml})$, a significant increase in the amount of FITC-dextran in the incubation solution is observed. In the case of an SDS concentration of $100 \mu \mathrm{g} / \mathrm{ml}$, a similar effect is observed but much less expressed. Subsequently, there is a gradual release of FITC-dextran into the incubation solution in all samples. The release of FITC-dextran in trace amounts is observed, when PMC is incubated in water, a similar result for capsules of the composition (PSS/PAH) ${ }_{3}$ was described in other works $(1,2,3)$. The highest release of FITC-labeled dextran is observed at an SDS concentration of $3000 \mu \mathrm{g} / \mathrm{ml}$, and the main release is observed in the first $3 \mathrm{~h}$ of incubation. The release of FITC-dextran in an SDS solution with a concentration of $100 \mu \mathrm{g} / \mathrm{ml}$ is more uniform. Differences in the release of dextran at concentrations of $100 \mu \mathrm{g} / \mathrm{ml}$ and $3000 \mu \mathrm{g} / \mathrm{ml}$ are observed due to the fact that in a higher concentration of SDS microcapsules are destroyed faster (after $3 \mathrm{~h}$ ), which leads to a faster release of the substance in the first hours of incubation. The total release of dextran in $24 \mathrm{~h}$ at an SDS concentration of $3000 \mu \mathrm{g} / \mathrm{ml}$ is $54 \%$ of the amount of the encapsulated substance; at an SDS concentration of $100 \mu \mathrm{g} / \mathrm{ml}$, the dextran release is $44 \%$.

\section{Conclusions}

The work demonstrated the destruction of the PMC using SDS. It was found that in a high concentration SDS solution $(3000 \mu \mathrm{g} / \mathrm{ml})$, microcapsules begin to be destroyed after $3 \mathrm{~h}$ of incubation, and almost destroyed in $24 \mathrm{~h}$. A lower concentration of SDS $(100 \mu \mathrm{g} / \mathrm{ml})$ also leads to the destruction of capsules, however, this process is more prolonged in time and not so expressed. At SDS concentrations ranging from 10 to $50 \mu \mathrm{g} / \mathrm{ml}$, the destruction of microcapsules was not observed. The study of the release of FITC-labeled dextran from microcapsules showed that at a SDS concentration of $3000 \mu \mathrm{g} / \mathrm{ml}$, the main release occurs during the first hours of incubation and in total for $24 \mathrm{~h}$ is $54 \%$ of the amount of the encapsulated substance. At an SDS concentration of $100 \mu \mathrm{g} /$ $\mathrm{ml}$, the dextran release occurs evenly and is $44 \%$ in $24 \mathrm{~h}$. These data correlate well with the results of an experiment to study the destruction of microcapsules. The cause of the destruction of the microcapsule may be the electrostatic interaction of SDS molecules with uncompensated site of PAH microcapsules, which leads to the destruction of the PMC.

\section{Appendix}

The images of polyelectrolyte microcapsules in SDS solution (concentration 0, 10, 50, 100 and $3000 \mu \mathrm{g} / \mathrm{ml}$ ) over time (after 0, 10, 30, 60, 180 and 1440 (24 h) minutes). 


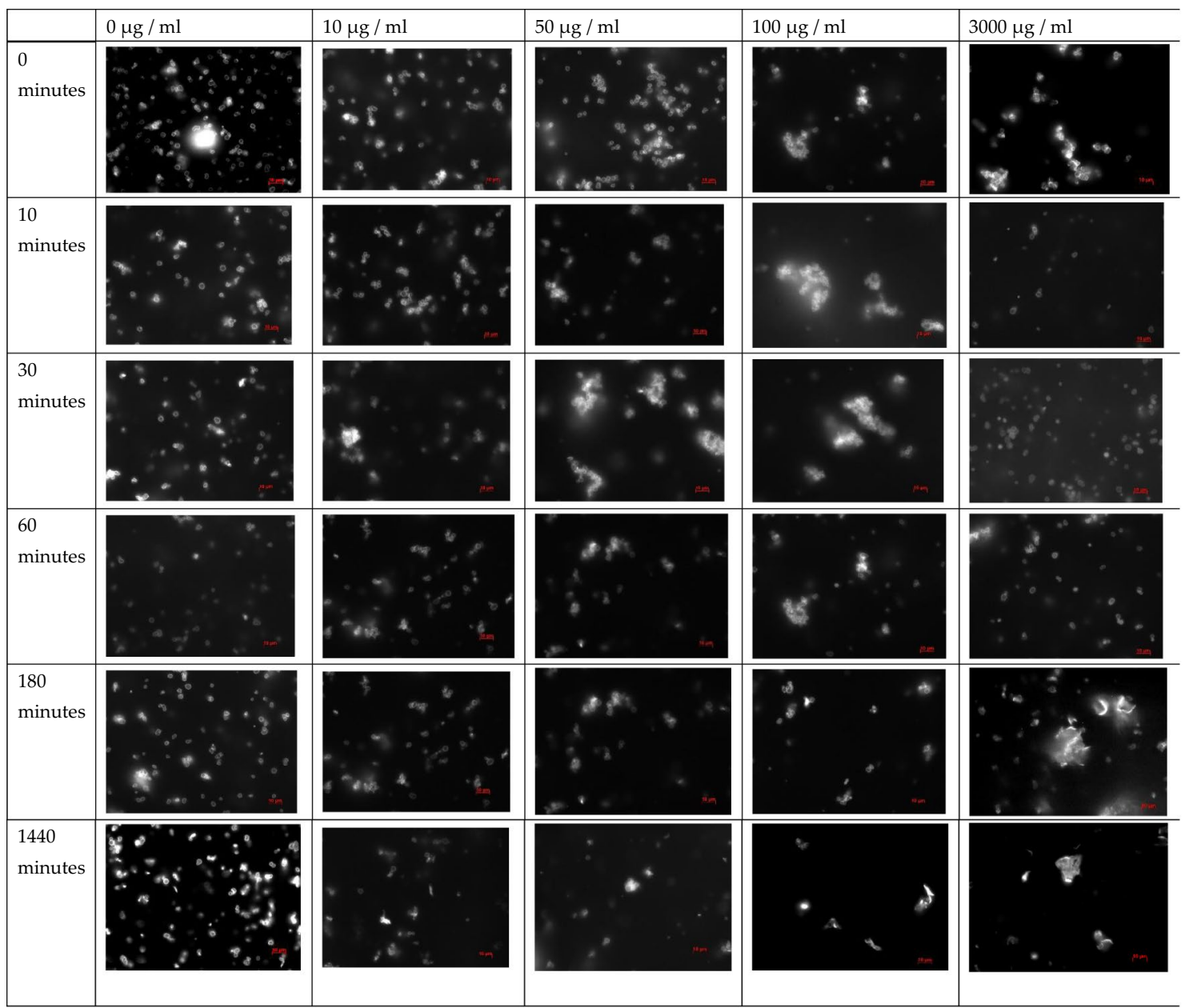

Received: 21 December 2021; Accepted: 23 February 2022

Published online: 07 March 2022

\section{References}

1. Donath, E., Sukhorukov, G. B., Caruso, F., Davis, S. A. \& Möhwald, H. Novel hollow polymer shells by colloid-templated assembly of polyelectrolytes. Angew. Chemie Int. Ed. https://doi.org/10.1002/(sici)1521-3773(19980904)37:16\%3c2201::aid-anie2201\%3e3.3. co;2-5 (1998).

2. Wang, C. et al. Microcapsules for controlled release fabricated via layer-by-layer self-assembly of polyelectrolytes. J. Exp. Nanosci. 3, 133-145. https://doi.org/10.1080/08927020802036005 (2008).

3. De Geest, B. G., Sanders, N. N., Sukhorukov, G. B., Demeester, J. \& De Smedt, S. C. Release mechanisms for polyelectrolyte capsules. Chem. Soc. Rev. 36, 636-649. https://doi.org/10.1039/B600460C (2007).

4. Johnston, A. P. R., Cortez, C., Angelatos, A. S. \& Caruso, F. Layer-by-layer engineered capsules and their applications. Curr. Opin. Colloid Interface Sci. 11, 203-209. https://doi.org/10.1016/j.cocis.2006.05.001 (2006).

5. Zheludkevich, M. L., Shchukin, D. G., Yasakau, K. A., Möhwald, H. \& Ferreira, M. G. S. Anticorrosion coatings with self-healing effect based on nanocontainers impregnated with corrosion inhibitor. Chem. Mater. 19, 402-411. https://doi.org/10.1021/cm062 066k (2007).

6. Kartsonakis, I. A., Danilidis, I. L., Pappas, G. S. \& Kordas, G. C. Encapsulation and release of corrosion inhibitors into titania nanocontainers. J. Nanosci. Nanotechnol. 10, 5912-5920. https://doi.org/10.1166/jnn.2010.2571 (2010).

7. Wang, X. \& Zhao, J. Encapsulation of the herbicide picloram by using polyelectrolyte biopolymers as layer-by-layer materials. J. Agric. Food Chem. 61, 3789-3796. https://doi.org/10.1021/jf4004658 (2013).

8. Santos, J. L., Nouri, A., Fernandes, T., Rodrigues, J. \& Tomás, H. Gene delivery using biodegradable polyelectrolyte microcapsules prepared through the layer-by-layer technique. Biotechnol. Prog. 28, 1088-1094. https://doi.org/10.1002/btpr.1576 (2012).

9. Borodina, T. N. et al. Polyelectrolyte microcapsules as the systems for delivery of biologically active substances. Biochem. Suppl. Ser. B Biomed. Chem. 2, 88-93. https://doi.org/10.1007/s11828-008-1010-3 (2008).

10. Sukhorukov, G. B., Antipov, A. A., Voigt, A., Donath, E. \& Mhwald, H. pH-controlled macromolecule encapsulation in and release from polyelectrolyte multilayer nanocapsules. Macromol. Rapid Commun. 22, 44-46. https://doi.org/10.1002/1521-3927(20010 101)22:1\%3c44::AID-MARC44\%3e3.0.CO;2-U (2001).

11. Skirtach, A. G., Antipov, A. A., Shchukin, D. G. \& Sukhorukov, G. B. Remote activation of capsules containing ag nanoparticles and ir dye by laser light. Langmuir 20, 6988-6992. https://doi.org/10.1021/la048873k (2004).

12. Bukreeva, T., Orlova, A., Sulyanov, S., Grigoriev, Y. \& Dorovatovskii, P. A New Approach to Modification of Polyelectrolyte Capsule Shells by Magnetite Nanoparticles. Crystallogr. Rep. 56, 880-883. https://doi.org/10.1134/S1063774511050051 (2011). 
13. Marchenko, I. V., Plotnikov, G. S., Baranov, A. N., Saletskii, A. M. \& Bukreeva, T. V. Formation and destruction of polyelectrolyte microcapsules modified by rhodamine 6G. J. Surf. Investig. X-ray Synchrotron Neutron Tech. 4, 95-98. https://doi.org/10.1134/ S1027451010010155 (2010).

14. Gulyaev, Y. V. et al. Decapsulation of polyelectrolyte nanocomposite microcapsules by pulsed microwave effect. J. Commun. Technol. Electron. 60, 1286-1290. https://doi.org/10.1134/S1064226915110042 (2015).

15. Demina, P. A., Degtyareva, E. V., Kuzmicheva, G. M. \& Bukreeva, T. V. Polyelectrolyte microcapsules modified with nanosized titanium dioxide for targeted drug delivery. Chem. Technol. Inorg. Mater. 4, 73-79 (2014).

16. Musin, E. V., Kim, A. L., Dubrovskii, A. V., Kudryashova, E. B. \& Tikhonenko, S. A. Decapsulation of dextran by destruction of polyelectrolyte microcapsule nanoscale shell by bacillus subtilis bacteria. Nanomaterials 10, 12. https://doi.org/10.3390/nanol 0010012 (2019).

17. Sharipova, A. et al. The Use of polymer and surfactants for the microencapsulation and emulsion stabilization. Colloids Interfaces 1, 3. https://doi.org/10.3390/colloids1010003 (2017).

18. Duan, G., Haase, M. F., Stebe, K. J. \& Lee, D. One-Step generation of salt-responsive polyelectrolyte microcapsules via surfactantorganized nanoscale interfacial complexation in emulsions (SO NICE). Langmuir 34, 847-853. https://doi.org/10.1021/acs.langm uir.7b01526 (2018).

19. Hammouda, B. Temperature effect on the nanostructureof SDS micelles in water. J. Res. Natl. Inst. Stand. Technol. 118, 151. https:// doi.org/10.6028/jres.118.008 (2013).

20. Sharipova, A. et al. Dynamics of adsorption of polyallylamine hydrochloride/sodium dodecyl sulphate at water/air and water/ hexane interfaces. Colloids Surfaces A Physicochem. Eng. Asp. 391, 112-118. https://doi.org/10.1016/j.colsurfa.2011.02.052 (2011).

21. Yoshida, E. Self-assembly of poly(allylamine hydrochloride) through electrostatic interaction with sodium dodecyl sulfate. Colloid Polym. Sci. 288, 1321-1325. https://doi.org/10.1007/s00396-010-2255-1 (2010).

\section{Author contributions}

Conceptualization, S.T., E.M.; Data curation, A.K. and S.T.; Formal analysis, E.M., A.D.; Investigation, A.D. and E.M.; Methodology, A.K., S.T., A.D. and E.M.; Project administration, S.T.; Supervision, S.T.; Visualization, A.K., E.M.; Writing - original draft, A.D. and A.K.; Writing - review and editing, A.K., E.M., A.D. and S.T.

\section{Funding}

This research was funded by State assignment of Russian Federation: 075-01027-22-00.

\section{Competing interests}

The authors declare no competing interests.

\section{Additional information}

Correspondence and requests for materials should be addressed to S.A.T.

Reprints and permissions information is available at www.nature.com/reprints.

Publisher's note Springer Nature remains neutral with regard to jurisdictional claims in published maps and institutional affiliations.

(c) (i) Open Access This article is licensed under a Creative Commons Attribution 4.0 International License, which permits use, sharing, adaptation, distribution and reproduction in any medium or format, as long as you give appropriate credit to the original author(s) and the source, provide a link to the Creative Commons licence, and indicate if changes were made. The images or other third party material in this article are included in the article's Creative Commons licence, unless indicated otherwise in a credit line to the material. If material is not included in the article's Creative Commons licence and your intended use is not permitted by statutory regulation or exceeds the permitted use, you will need to obtain permission directly from the copyright holder. To view a copy of this licence, visit http://creativecommons.org/licenses/by/4.0/.

(c) The Author(s) 2022 